\title{
"Vivendo o SUS": uma experiência prática no cenário da atenção básica
}

\section{PALAVRAS-CHAVE \\ - Reforma Curricular. \\ - Atenção Básica \\ - Ensino Médico \\ - ntegralidade em Saúde}

\section{KEY WORDS}

- Curricular Reform

- Basic Care

- Medical Education

- Integral Health

Recebido em: 31/05/2009 Aprovado em: 11/08/2009

\section{"Experiencing the Single Health System ": a practical experience in primary health care in Brazil}

\author{
Rosana Maria Paiva dos Anjos ${ }^{\mathrm{I}}$ \\ Reinaldo José Gianini ${ }^{\mathrm{I}}$ \\ Fátima Cristina Minari ${ }^{\mathrm{I}}$ \\ Ana Helena Seabra de Luca ${ }^{\mathrm{I}}$ \\ Mauro Paiva Rodrigues ${ }^{\mathrm{I}}$
}

\begin{abstract}
R E S U M O
O projeto "Vivendo o SUS", realizado com a participação dos alunos do primeiro ano do curso de Medicina da PUC/SP, visou introduzir os estudantes no contexto das ações do sistema público de saúde e suas relações com a população local, no município de Sorocaba. Posteriormente, com a reforma curricular do curso de Medicina, foi construído o Módulo de Prática em Atenção à Saúde (PAS), com desenvolvimento nos seis anos do curso. A realização desse projeto foi importante para estimular e nortear o processo de mudança curricular, por meio da execução de uma atividade que propiciou exercícios de reflexão sobre a experiência vivenciada pelo estudante de Medicina, estimulando a percepção de situações como o cuidado e a organização do processo de trabalho na atenção básica, as relações na equipe de saúde e as informações como ferramentas para o planejamento. Atualmente, o ensino médico, inserido no espaço da Atenção Básica, contribui na produção de conhecimentos para o aprimoramento do sistema de saúde local e, intervindo na realidade, forma um profissional mais habilitado e comprometido com a comunidade.
\end{abstract}

\section{A B S T R A C T}

The project "Vivendo o SUS" (Experiencing the Single Health System ), including participation by first-year medical students at the Catholic University in São Paulo, aimed to introduce undergraduates to activities in the public health system and its relationship to the local population in the city of Sorocaba. Following a curricular reform in the medical school, a Healthcare Practice Module was developed for the full six years of undergraduate medical training. The project has been important for stimulating and orienting the curricular change, implementing an activity than encourages students to reflect on their experience. It fosters the perception of situations like patient care and organization of the work flow in primary care, teamwork in health, and information as a planning tool. Medical education, now part of the Primary Care context, contributes to the production of knowledge for improving the local health system while impacting reality and training health professionals that are better prepared and committed to the community. 


\section{INTRODUÇÃO}

A conquista da saúde como direito verdadeiro de cada cidadão, ainda que este último esteja amparado pela legislação, representa um constante desafio, que só será superado com a adequada formação de profissionais para a área da saúde. As atuais diretrizes curriculares dos cursos de Medicina salientam o perfil do formando como: "médico com formação generalista, humanista, crítica e reflexiva, capacitado a atuar, pautado em princípios éticos, no processo saúde-doença em seus diferentes níveis de atenção ${ }^{\prime 1-3}$.

A construção do SUS é norteada pelos princípios de universalidade, equidade e integralidade, por meio das disposições contidas na Lei 8.080, de 19/09/90, que dispõe sobre as condições para promoção, proteção, recuperação da saúde e organização do funcionamento dos serviços correspondentes. O sistema dá importância ao reconhecimento dos problemas de saúde da população de uma área delimitada, considerando as diversidades locais ${ }^{4-6}$

Entre as atividades do SUS, uma das mais importantes é o Programa Saúde da Família (PSF), criado pelo Ministério da Saúde em 1994 e catalogado como estratégia, buscando se diferenciar dos programas tradicionais já produzidos, com o propósito de expandir a cobertura, em saúde, da população brasileira e, consequentemente, sua força de trabalho ${ }^{7,8}$.

A Faculdade de Ciências Médicas de Sorocaba abrange os cursos de Medicina e Enfermagem, e integra o Centro de Ciências Médicas e Biológicas da Pontifícia Universidade Católica de São Paulo (CCMB - PUC/SP). As atividades acadêmicas se iniciaram em 1951, transformando Sorocaba na primeira cidade do interior do País a sediar um curso médico 9 .

A construção do currículo das disciplinas na faculdade, bem como a dos de outras escolas médicas brasileiras, seguiu a orientação da época, isto é, do século passado. A atenção estava organizada por especialidades, centrada na doença e no hospital, fragmentando o cuidado e propiciando a desresponsabilização, pois não existe visão do todo - cada profissional cuida da sua parte e, na concepção restrita de saúde, presta uma "assistência medicalizadora", com limitação do atendimento ambulatorial para os casos em que a internação se faz necessária, com pouca ênfase nas práticas de prevenção, promoção à saúde e reabilitação ${ }^{10}$.

O ensino, por sua vez, era centrado no professor, com aulas expositivas magistrais para grandes grupos de estudantes. $\mathrm{O}$ currículo era estruturado em ciclos estanques: o básico, e o clínico-profissional, ambos modulares e não integrados entre si, tampouco com outros serviços de saúde. O ser humano, para fins de estudo, era dividido por sistemas ou aparelhos, segundo critérios anatômico-funcionais, com valorização do modelo biomédico clínico, porém com pouco espaço para os aspectos sociais, psicológicos e coletivos ${ }^{11,12}$

Havia um descompasso entre as necessidades das pessoas, os princípios e diretrizes do SUS e a universidade, que "praticava o ensino médico" nos hospitais universitários e ambulatórios de maior complexidade, limitando e direcionando o interesse e as perspectivas profissionais futuras às especialidades médicas, ao paciente particular e à doença. Os usuários do SUS eram "objetos para a aprendizagem", servindo de treinamento para os universitários da área médica. Prática perversa que, ainda hoje, é mantida e produzida na maioria das escolas médicas no Brasil ${ }^{13,14}$.

A busca de mudanças e o desafio da reforma curricular, com a adoção de novas metodologias, mais reflexivas, participativas e holísticas, tiveram início em 2001, pela direção do CCMB-PUC/SP, alavancados pelo Programa de Incentivo às Reformas Curriculares dos Cursos de Medicina, o Promed ${ }^{15-17}$

Assim, o processo permitiu criar e executar ações estratégicas para as necessárias mudanças no currículo vigente, iniciando o complexo trabalho de reconstrução para a transformação das concepções de alunos e professores ${ }^{10,18-22}$. Isto os dispôs a receberem os primeiros impactos de um ensino que utiliza diferentes modelos de atenção em saúde: explicativos dos processos saúde-doença, desenvolvidos pelo método da aprendizagem baseada em problemas, de conteúdo integrado, de conhecimentos interdisciplinares, contextualizados em cenários reais, com valorização da postura profissional, das habilidades e das atitudes morais e éticas ${ }^{23-26}$.

Uma das formas de alcançar mudanças no campo da saúde foi aproximar a universidade dos serviços de saúde, introduzindo o aluno de Medicina nas unidades da rede, para conhecerem a realidade e as práticas de saúde também coletivamente, isto é, com pessoas que, juntas, refletissem sobre e vivenciassem experiências de trabalho em saúde. Tais experiências, conquanto possam produzir contato com o desconforto, são capazes de construir novos pactos de convivência, efetivando a universalidade dos serviços de saúde, da gestão democrática e das práticas integrais de saúde $27-29$.

Intentando tais mudanças, em 2003, 2004 e 2005 foi desenvolvido o projeto "Vivendo o SUS", que, em 2006, com a reforma curricular, originou o Módulo de Prática em Atenção à Saúde (PAS), criado para ser posto em prática nos seis anos do curso de Medicina, inclusive no estágio curricular denominado internato, e que se integra com os outros módulos, em cada ano do curso de graduação, por meio de eixos temáticos e de habilidades. Com 
realização em vários cenários de práticas, nos diferentes níveis de atenção à saúde, tem, como prioritário, o Programa de Saúde da Família - núcleo central de atenção "à família e de promoção da saúde" ${ }^{\prime 30,31}$.

Atualmente, os alunos da primeira série do curso de Medicina, em grupos de 20, atuam na área de uma unidade de saúde municipal durante todo o curso. Preceptores acompanham as atividades de visita domiciliar (VD), que perfazem cinco famílias por aluno. A seleção das famílias pelos agentes comunitários de saúde prioriza gestantes, recém-nascidos, crianças menores de cinco anos e adultos e idosos portadores de doenças crônicas, acamados ou que morem sozinhos. Os alunos trabalham em duplas, em corresponsabilidade, totalizando dez famílias nas atividades desenvolvidas durante a semana. Estas são planejadas em grupos e executadas na área de territorialidade da unidade de saúde, tendo como meta realizar intervenções de saúde na família, planejar e executar ações comunitárias e de rastreamento, participar ativamente dos trabalhos cotidianos da unidade-base e integrar ações de saúde enfocando os centros comunitários locais (escolas, creches e asilos).

Este ano, está sendo construído o projeto para o internato, com dois anos de duração, que terá início em 2010. De acordo com o Projeto Pedagógico da Reforma Curricular, embasado nas diretrizes do MEC/MS, em consonância com as diretrizes da Abem e CFM, a Saúde Coletiva deve contar com 20\% da carga horária nesse estágio para a prática da Medicina Geral e Comunitária. Assim, cada aluno acompanhará um médico do PSF, participará dos programas de saúde, da orientação médica coletiva (OMC) e da consulta médica ampliada, reformulando as visitas domiciliares e aprofundando seu conhecimento em Epidemiologia Clínica e em Políticas de Saúde.

\section{PROJETO “VIVENDO O SUS"}

O “Vivendo o SUS", pensado em 2001 e iniciado em 2003, com a participação dos alunos do primeiro ano de Medicina da Faculdade de Ciências Médicas de Sorocaba, foi reestruturado em 2004 e reaplicado no ano seguinte, em 2005, também para o terceiro ano do curso de Medicina. Tal projeto visou introduzir os estudantes no contexto das ações do sistema público de saúde e das suas relações com a população local no município de Sorocaba.

\section{Por que fazer?}

O projeto norteou a construção de atividades da atenção básica à saúde, em cenários reais, envolvendo o corpo docente e discente do curso de Medicina na graduação para: (1) interagir e vincular a universidade com os serviços de saúde e a comunida- de, inserindo o aluno de Medicina no cotidiano de trabalho em unidades de saúde - a Unidade de Saúde da Família (USF) e as Unidades Básicas de Saúde (UBS); (2) criar a oportunidade de conhecer os modelos de atenção à saúde de uma população, $\mathrm{o}$ trabalho em equipe, o planejamento em saúde, e de refletir sobre esses modelos; (3) possibilitar a observação do trabalho de uma equipe de PSF, no domicílio e na comunidade, conhecendo a necessidade de saúde das pessoas; (4) sensibilizar para o desenvolvimento de práticas educacionais e pedagógicas que facilitem o compartilhar de conhecimentos e informações.

\section{Com quem fazer?}

Para efetivar as ações do referido projeto, a direção da Faculdade de Ciências Médicas do CCMB estabeleceu parceria com a Secretaria da Saúde do município de Sorocaba. Assim, a disciplina de Medicina Preventiva e Social (DMPS) pôde viabilizar a dinâmica de trabalho denominada "Vivendo o SUS" junto à coordenação técnica do Programa de Saúde da Família (PSF) e das Unidades Básicas de Saúde (UBS) da Secretaria Municipal de Saúde de Sorocaba.

Na universidade, o plano global das ações "Vivendo o SUS" foi apresentado aos membros da comissão de série do primeiro ano do curso de Medicina. Depois da aprovação, foi solicitada a identificação dos nove professores do curso de graduação e de diferentes disciplinas que participariam das ações propostas. As mudanças da prática pedagógica têm esbarrado na resistência de muitos professores, com tendências pedagógicas tradicionais, que refletem sua concepção sobre as funções profissionais e o modo como devem ser desenvolvidas. Muitos ainda ensinam, segundo os métodos que dominam, os conteúdos que acreditam que devam ser ensinados, cultivando o objetivismo tecnológico especializado, descompromissado com o social e, sem visão horizontal, se distanciam da realidade das pessoas, da comunidade e do sistema público de saúde. Assim, esse projeto também visou contemplar o professor de outras áreas e especialidades, introduzindo esse profissional, junto com os alunos, no contexto da capacitação da atenção básica de saúde.

\section{Como fazer?}

Na metodologia definida em 2004, os alunos do primeiro ano do curso de Medicina foram divididos em dois grupos de 50, para desenvolverem práticas com duração de 40 horas, em uma semana, em período integral.

O primeiro grupo acompanhou o trabalho rotineiro e diário dos agentes comunitários de saúde (ACS), durante dois dias, divididos em quatro Unidades de Saúde da Família do município de 
Sorocaba. As equipes foram compostas por dois alunos para cada ACS. Como instrumentos de trabalho, foram elaborados um boletim para a coleta de dados e um roteiro de relatório, para a consolidação, na apresentação final da atividade. Observe-se que esses instrumentos simples não interferem na observação nem na reflexão da ação, servem somente de apoio para a tarefa proposta. O segundo grupo, nos dois primeiros dias, foi dividido em cinco Unidades Básicas de Saúde (UBS) e estava preparado para efetuar ações de "acolhimento" e "cadastramento" dos usuários presentes nesses serviços.

Sempre que se iniciam os trabalhos, solicita-se ao coordenador da UBS que informe aos alunos e professores as características da unidade local, como área de abrangência, população atendida, membros da equipe da unidade, número de consultas realizadas pelos setores, programas efetuados, fluxo da unidade e perspectivas do trabalho. Cada aluno, já orientado a promover uma "ação de acolhimento" com um usuário da UBS, segue o trajeto de assistência do acolhido na unidade, realizada pelos profissionais de saúde, observando e anotando os dados de resolubilidade quanto ao problema individual de saúde, até o momento em que deixa o serviço. A seguir, é feito o cadastramento da família, na visita domiciliar efetuada em duplas de alunos, conforme a definição prévia da coordenação da DMPS. Assim, cada participante tem a missão de:

1. aplicar um questionário de acolhimento a um usuário da UBS;

2. acompanhar um paciente em sua consulta ou procedimento pela UBS;

3. fazer o cadastramento;

4. realizar duas visitas domiciliares.

Por meio dos instrumentos utilizados pelas duplas de alunos, são colhidos dados como:

1. número de famílias visitadas e de pessoas em cada residência;

2. perfil dessa população, segundo faixa etária e sexo;

3. situação socioeconômica da população visitada (situação aclarada por meio de perguntas sobre renda, escolaridade e profissão;

4. número de gestantes;

5. saúde da população (dados levantados por meio de perguntas sobre o número de pessoas com carteira de vacinação em dia, doenças referidas e observação das condições ambientais, de moradia e saneamento).

Nos dois dias seguintes, em sistema de rodízio, os alunos que visitaram a USF vão para uma UBS, e vice-versa. Tal oportunidade permite que o aluno entenda, na prática, as semelhanças e diferenças entre as duas estratégias na atenção à saúde, em cenários reais, no trabalho cotidiano, nas relações com o usuário e a comunidade.

Um docente do curso de Medicina fica responsável pelos alunos, em cada uma das unidades de saúde, como facilitador para a realização das atividades propostas.

Os alunos são treinados para as ações do "Vivendo o SUS" durante o horário regular da disciplina de Medicina Preventiva e Social, momento em que são apresentadas as atividades programadas e efetuadas as divisões dos grupos de alunos, por unidade de saúde. Todos são orientados a conhecer os locais de trabalho de campo durante a semana. Num segundo momento, são revistas as ações propostas para cada grupo e apresentados os instrumentos de coleta de dados, preenchidos durante a atividade.

A capacitação dos professores do curso de Medicina de outras áreas, os quais se oferecem para o trabalho proposto, é realizada com uma semana de antecedência. São preparadas pastas etiquetadas, destinadas a cada professor, contendo o plano de operacionalização da atividade "Vivendo o SUS"; um folheto orientador indica, passo a passo, o "aquecimento", ou seja, a forma de introdução no serviço de atenção básica a ser efetuado por cada grupo de alunos, juntamente com as equipes de trabalhadores locais (unidades de saúde).

Ao término dessa atividade, na atenção básica, são aplicados aos alunos dois questionários: um, para coletar informações das experiências individuais, e outro, aplicado em grupos de trabalho, na plenária, para verificar se as metas esperadas de aproveitamento foram atingidas. Assim, os alunos apresentam a consolidação das atividades no quinto dia, ao se encerrar a ação "Vivendo o SUS". O evento conta com a presença do secretário de Saúde municipal e a de todos os funcionários municipais que participam do projeto.

A seguir, são apresentados alguns dos resultados das ações desenvolvidas em 2004. Em 2005, os consolidados mantiveram o padrão, com melhoria do preenchimento dos instrumentos trabalhados e na apresentação final, com a diversidade da interferência criativa de cada grupo de alunos.

\section{Quais os resultados obtidos?}

O consolidado das atividades realizadas nas USF pelos alunos que acompanharam os agentes comunitários demonstrou que, no período da ação, 1.328 famílias foram visitadas e mostrou dados de saúde, das condições socioeconômicas e ambientais.

Nas atividades das UBS, foi feito o acolhimento de 98 pessoas, cujo atendimento nos diversos setores da UBS foi acompa- 
nhado. Foi, também, colhida a opinião desses usuários sobre a atenção recebida na unidade de saúde e realizada a visita domiciliar para o cadastramento dessas famílias, com o registro das condições socioambientais.

O perfil dessa comunidade e as situações de saúde encontradas permitiram reflexões e ações de promoção à saúde. Os estudantes que participaram do "Vivendo o SUS" perceberam o alcance da atenção básica na realidade social, com troca de experiências e ajudas mútuas, firmando compromisso com as pessoas e com a cidadania.

Com um novo olhar para as diversidades, são incorporados conteúdos, ideias e disposições para a ação. Assim, cada cenário e cada situação produzem associações construtivas para uma participação mais dinâmica na atenção às necessidades do coletivo e na formação de habilidades e atitudes do futuro profissional.

\section{Quanto às atividades realizadas nas Unidades de Saúde da Família}

Os 50 alunos, divididos nas quatro Unidades de Saúde da Família (USF) do município de Sorocaba -unidades de Aparecidinha, Vila Sabiá, Vitória Régia e Habiteto -, visitaram, em média, de 11 a 12 famílias por dia de atividade. Este número variou de 9 a 20 famílias por dia, de acordo com o horário, o dia da visita, a presença de moradores na casa, o agendamento do agente comunitário de saúde e a aceitação das pessoas (motivos particulares da família). Foram designados dois dias para as visitas domiciliares, guiadas pelos agentes comunitários de saúde.

A partir dessas visitas na área periférica do município de Sorocaba, os alunos verificaram que $72,3 \%$ das famílias declararam possuir renda média de um a três salários mínimos; $65,3 \%$ possuíam cinco moradores em sua residência, mas havia famílias com 11 pessoas na casa. Nas residências visitadas, foram identificadas 86 pessoas que não receberam todas as vacinas preconizadas para a sua faixa etária, sexo e condições de saúde, embora a grande maioria $(90,7 \%)$ tenha apresentado a carteira de vacinação completa. Essa ação permitiu aos alunos a participação nas tarefas educativas e de promoção da saúde, importantes para a redução do risco de contrair doenças com potencial epidêmico e que podem ser prevenidas.

Ainda no tocante às situações de saúde - num total de 304 apresentadas pelas pessoas durante essas visitas, foram observadas (ou constatadas) doenças de magnitude, como hipertensão arterial (HA) (26\%), diabetes mellitus (DM) (24\%) e associação de HA e DM (24\%). Esses problemas de saúde mostram algumas das necessidades dessa comunidade, sensibilizando para a obtenção de assistência à saúde, tratamento das doenças e alívio dos sofrimentos individuais e coletivos.

\section{Quanto às atividades realizadas nas Unidades Básicas de Saúde}

Os outros 50 alunos foram distribuídos por cinco unidades de saúde do município de Sorocaba, selecionadas entre as 27 existentes. Nessa escolha, foram considerados os antecedentes locais de acolhimento de alunos e de tradição na atenção e vigilância à saúde.

Dos 98 usuários acolhidos, mais de 70\% eram do sexo feminino, confirmando os registros de que as mulheres têm maior percepção de doenças e, assim, procuram mais a assistência médica, enquanto os homens o fazem com frequência menor.

A maioria dos entrevistados (47\%) tem entre 20 e 60 anos, na faixa de idade ligada à produtividade, e $25 \%$ dos acolhidos recebem até três salários mínimos. Na verificação desse parâmetro de renda familiar, chama atenção o grande número de campos deixados em branco (51\%), referentes às pessoas que preferiram não responder a essa questão e aos alunos que se sentiram desconfortáveis para perguntar a situação financeira da família. Mais de uma família informou estar, no momento, sem renda e sem emprego. Também a maioria dos acolhidos (41\%) não referiu sua escolaridade. Entre os que a referiram, mais de $40 \%$ das pessoas eram analfabetas ou tinham cursado o ensino fundamental sem completá-lo, e apenas 3\% chegaram ao ensino superior.

No atendimento da UBS, os setores clínicos de consulta médica foram os mais procurados pelos acolhidos; menos de $10 \%$ vieram para os programas de saúde e imunização. Após os cuidados da atenção na UBS, foi realizada uma pesquisa de opinião entre os usuários acolhidos, por meio de uma pontuação de zero a dez, sobre a qualidade do atendimento recebido na Unidade Básica de Saúde. Aproximadamente $90 \%$ deles, ou seus responsáveis, pontuaram entre sete e dez; somente $11 \%$ consideraram o atendimento regular ou ruim, pontuando seis ou menos. Ficou claro que a grande maioria dos usuários está satisfeita com o atendimento recebido na rede básica; mesmo assim, cerca de $10 \%$ das pessoas esperam mais do sistema, que deve ser aprimorado.

A escuta da população e dos trabalhadores da saúde contribui para identificar os entraves na assistência prestada à população e nos serviços locais e, principalmente, para refletir sobre esses entraves e tentar buscar soluções para que esses nós críticos deixem de existir.

Durante a visita domiciliar, 34\% dos moradores declararam não ter doença alguma na família. Foram registrados 48 problemas de saúde, entre os quais depressão, problemas ortopédicos, gripe, enxaqueca, alergia, hipertensão e hepatite. Esse campo de 
pesquisa sobre a doença referida na família ficou em branco em cerca de $50 \%$ dos formulários, ou seja, entrou na análise como dado ignorado. Essa verificação remete ao fato e à necessidade de que o aluno da área de saúde deve desenvolver habilidades para preencher adequadamente os instrumentos de investigação de saúde coletiva, registrando tudo, mesmo quando a questão resulta negativa, ou seja, não aponta doenças.

Esses dados ajudam os acadêmicos a construir o perfil da população que procura a atenção básica de saúde e necessita de seus serviços, entendendo que tais informações auxiliam no planejamento em saúde, para a implantação de programas de assistência mais adequados, que atendam às doenças prevalentes, buscando maneiras de promover saúde e prevenir doenças, num trabalho integrado, para um impacto positivo na sobrevida e na qualidade de vida das pessoas. Amaioria da população acolhida tem uma renda pequena, o que lhe torna necessário e fundamental o acesso ao Sistema Único de Saúde. Por outro lado, também é importante que os alunos constatem que precisam desenvolver habilidade na técnica da entrevista e da visita domiciliar, assim como no completo preenchimento dos instrumentos de informação em saúde.

Nessa última atividade, dois alunos não conseguiram completar sua missão nesse bloco devido a problemas particulares, mas retomaram a participação nas demais ações.

\section{Quanto à experiência individual dos alunos}

Mais de $60 \%$ dos alunos apontaram não ter encontrado dificuldades de locomoção para as unidades onde realizaram as atividades. Os 30\% que se referiram a problemas no transporte até as unidades de saúde citaram, entre outros entraves, dificuldade de encontrar os endereços, já que as unidades estão em áreas periféricas da cidade; e a utilização de ônibus coletivos, uma vez que não dispunham de carro ou carona e não conseguiram alugar veículos em grupos (por falta de organização) ou, mesmo, não dispunham de recursos financeiros para isso. Nesse caso, a proposta foi mostrar aos alunos a grande dificuldade enfrentada pelos pacientes que, ao se deslocarem para outros serviços de saúde - geralmente de maior complexidade -, nem sempre são prontamente atendidos; ao contrário, muitas vezes, são dispensados sem a menor consideração ou explicação.

Quanto à atenção da equipe multiprofissional local, mais de $90 \%$ dos alunos se sentiram bem recebidos. Nenhum deles relatou como ruim a recepção pela equipe de trabalhadores da saúde, mostrando, também, o bom envolvimento das equipes locais no projeto.
A maioria dos alunos (89\%) classificou como bom o serviço de atenção básica à saúde fornecido aos usuários com quem tiveram contato durante as atividades. Somente $2 \%$ dos clientes consideraram o serviço como regular ou ruim, o que corrobora a pesquisa de opinião dos usuários, que atribuem boa qualidade ao atendimento do SUS.

$\mathrm{Na}$ autoavaliação do empenho e interesse no desenvolvimento das ações do projeto "Vivendo o SUS", quase 90\% dos alunos consideraram boa a sua participação individual nas atividades realizadas, atribuindo uma pontuação entre sete e dez ao próprio desempenho.

O saldo desse trabalho o evidenciou como uma experiência bem-sucedida, observada e refletida sobre uma realidade que permitiu aos grupos conhecerem melhor o funcionamento das unidades visitadas e sua organização, incluindo o fluxo de atendimento do SUS.

\section{Quanto à experiência geral}

Na última atividade, foi realizada uma plenária com todos os alunos, coordenadores de unidade e agentes comunitários participantes. Os alunos foram divididos em nove grupos de trabalho, para discutir e apresentar suas experiências, bem como as informações colhidas e contextualizadas, com reflexões sobre facilidades e/ou dificuldades no desenvolvimento da atividade e possíveis soluções encontradas (Tabelas 1, 2 e 3). Após as apresentações, todos estavam emocionados, e a impressão geral era a de que os resultados obtidos superaram todas as expectativas.

Os grupos preencheram as fichas de avaliação sobre a atividade "Vivendo o SUS". Cem por cento dos alunos consideraram que foram atingidos os objetivos de:

1. desenvolver um trabalho em unidade de saúde, na atenção básica do sistema;

2. obter alguns conhecimentos quanto à caracterização de uma unidade de saúde da rede básica de atendimento de uma população;

3. conhecer e refletir sobre a realidade das famílias visitadas e cadastradas, com ênfase em suas características sociais, econômicas, culturais e epidemiológicas.

Para aproximadamente $90 \%$ dos alunos, foram atingidos outros objetivos, assim enunciados:

1. diferenciar as características de uma USF das de uma UBS;

2. introduzir o aluno no cotidiano de trabalho dos agentes comunitários de saúde;

3. praticar o Programa Saúde da Família, com ações de acolhimento, visita domiciliar e cadastramento. 
Tabela 1

Avaliação dos alunos de Medicina sobre o alcance dos objetivos atividade prática "Vivendo o SUS" em saúde

\begin{tabular}{lcc}
\hline Os objetivos foram atingidos ou não & & $\mathrm{N}-\%$ \\
\hline $\mathbf{N}$ (total) & sim & $\mathbf{1 0 0}$ \\
Desenvolver um trabalho na atenção básica & sim & 100 \\
Caracterizar uma unidade de saúde em sua área de territorialização & sim & 100 \\
Refletir sobre as situações da saúde e social das famílias visitadas e cadastradas & sim & 91 \\
Diferenciar uma USF de uma UBS & sim & 90 \\
Conhecer o cotidiano de trabalho dos agentes comunitários do PSF & parcialmente & 10 \\
Praticar ações do PSF - acolhimento/cadastramento & sim & 88 \\
Respeitar a autonomia do usuário do SUS e da família & parcialmente & 22 \\
Conhecer o sistema de referência e de contrarreferência no SUS & sim & 81 \\
& parcialmente & 19 \\
\hline
\end{tabular}

Tabela 2

Avaliação da proposta metodológica desenvolvida atividade prática "Vivendo o SUS" na atenção básica

No "Vivendo o SUS" ( $\mathrm{N}=100$ alunos)

$\mathrm{N}-\%$

A metodologia utilizada foi

$\begin{array}{cc}\text { boa } & 89 \\ \text { regular } & 11 \\ \text { ruim } & 0\end{array}$

O material utilizado (fichas e instrumentos) foi

$\begin{array}{cc}\text { ótimo } & 26 \\ \text { bom } & 54 \\ \text { regular } & 20 \\ \text { ruim } & 0\end{array}$

A infraestrutura utilizada (espaço físico, material de apoio) foi

$\begin{array}{cc}\text { ótima } & 12 \\ \text { boa } & 53 \\ \text { regular } & 25 \\ \text { ruim } & 10\end{array}$


Tabela 3

Avaliação dos aspectos positivos, negativos e sugestões da atividade prática "Vivendo o SUS" realizada no cenário da atenção básica

\begin{tabular}{|c|c|}
\hline No “Vivendo o SUS” (N = 100 alunos) & $\mathrm{N}-\%$ \\
\hline \multicolumn{2}{|l|}{ Três aspectos positivos* (mais citados) } \\
\hline troca de experiências & 100 \\
\hline interação com o agente comunitário & 91 \\
\hline aprendizagem contextualizada & 81 \\
\hline revisão de conceitos de trabalho em saúde & 71 \\
\hline inserção numa UBS/USF & 62 \\
\hline trabalho de campo - cadastramento & 61 \\
\hline \multicolumn{2}{|l|}{ Três aspectos negativos* (mais citados) } \\
\hline professores não integrados com as UBS & 43 \\
\hline falha na operacionalização de alguma ação & 23 \\
\hline chuva & 11 \\
\hline \multicolumn{2}{|l|}{ Sugestões para os próximos planejamentos } \\
\hline faculdade: providenciar transporte para as atividades & 47 \\
\hline professores: mais interessados e preparados & 32 \\
\hline maior carga horária para a atividade & 37 \\
\hline aumentar o $\mathrm{n}^{\mathrm{o}}$ proposto de acolhidos & 35 \\
\hline pontualidade no horário da plenária & 11 \\
\hline
\end{tabular}

* Mais de uma alternativa

Mais de $80 \%$ dos alunos consideraram, também, ter sido atingido o objetivo de valorizar os vínculos com o usuário do SUS e sua família, princípio este de notável importância para uma relação de confiança mútua entre médico e paciente, e de respeito à autonomia e à cidadania.

A metodologia utilizada foi considerada boa por $89 \%$ dos participantes.

Os aspectos positivos da ação mais citados foram aprendizado, troca de experiências e trabalho em campo com o agente comunitário.
Os aspectos negativos mais citados foram professores não integrados com a UBS, falha na operacionalização de alguma atividade e chuva.

Os coordenadores e agentes comunitários das UBS e USF também fizeram relatórios das atividades realizadas, apontando os limites e os pontos positivos dessa experiência, assim resumidos: "os alunos tiveram contato com unidades de saúde e com seus usuários, mostrando-se muito interessados. Foi atividade de grande valor para poderem viver o SUS. Estavam bem orientados e sabiam exatamente como proceder no seu trabalho. A 
equipe foi bem recebida pelos funcionários da unidade. A prática lhes permitiu conhecer a realidade da clientela SUS e a integração com a equipe de Saúde, estimulando o atendimento multiprofissional. Foi sugerido que os alunos, em ações futuras, permaneçam, no mínimo, quatro dias em cada local, a fim de melhor e mais eficaz participação em todas as atividades da unidade de saúde da família".

Nos dias seguintes, na continuidade do curso regular, os professores da disciplina de Medicina Preventiva e Social realizaram atividades complementares com os alunos, organizando os dados e aprimorando os instrumentos de trabalho de campo.

\section{DISCUSSÃO DOS RESULTADOS}

A formação médica ainda está associada à medicina privada, ao ambiente hospitalar e à negação dos aspectos não biológicos que interferem na saúde das pessoas. A prática profissional, para os alunos formados nas escolas tradicionais, ainda trata o usuário do sistema de saúde público como "objeto de estudo" e não como "sujeito singular", complexo e com espaço de autonomia $^{5,6,8}$.

Com os conhecimentos adquiridos em medicina, a prática médica é identificada com a científica, e os médicos se tornaram detentores de um saber oficial. Outros saberes ou práticas curadoras são rotulados de "não científicos" e, portanto, ineficazes ${ }^{30}$. A assistência à saúde adquire um modelo baseado em consultas médicas, procedimentos, equipamentos, medicamentos, na atenção especializada e hospitalar ${ }^{2,27}$.

A partir desse modelo, as expectativas criadas no aluno de Medicina diferem radicalmente do contexto real, tanto na ideia que ele tem de quem é empregador, como na do perfil de clientes, com as necessidades e problemas cotidianos que produzem ou agravam as doenças de suas vidas. A frustração resultante vem desse total despreparo do profissional para o reconhecimento do mercado de trabalho atual, das necessidades de saúde das pessoas, do coletivo, das diversas ferramentas, dos diferentes cenários, dos processos de trabalho e cuidados em saút $\mathrm{de}^{28,31,32}$.

Atualmente, busca-se um novo desenho, rumo à saúde coletiva e à integralidade, que consiga compreender, de forma ampliada, o processo de adoecimento e sofrimento das pessoas, e que propicie o surgimento de "uma nova abordagem clínica do usuário" frente às diferentes necessidades de cuidados nos serviços de saúde, permitindo a intervenção e a utilização do saber médico adequado a cada situação singular e sempre compromissado com a vida ${ }^{33,34,35}$
A reconstrução do papel dos profissionais de saúde perpassa por diferenças e conflitos entre o médico generalista e o médico especialista, pelo trabalho em equipe, pela atenção esperada pelo usuário, por procedimentos, pelo seguimento e por critérios de eficácia, entre outros ${ }^{32,37}$. A atenção básica deve ser resolutiva para $80 \%$ a $90 \%$ dos problemas de saúde, pois o doente está preocupado com a sua qualidade de vida, que é o seu critério para avaliar a eficácia médica; a intervenção predominante é a "biopsicossocial", e o resultado e, portanto, o seguimento é a médio e longo prazo. Já na atenção hospitalar, o paciente está a fim de "sobreviver": o seguimento é curto, e o resultado, imediato. Neste caso, predomina a intervenção no corpo, e o relacionamento com o paciente é pouco questionado, autoritário, e a eficácia da assistência é a "alta hospitalar". No pronto-socorro (PS) e no pronto atendimento (PA) - chamados serviços de urgência -, predomina o saber biomédico de causalidade buscada somente no plano biológico para a produção de um caminho terapêutico ${ }^{32}$.

A transformação da clínica na forma necessária, ampliada, é, atualmente, o maior dos desafios do SUS: tratar o doente e não a doença, ou seja, perceber o sujeito doente e ajudá-lo a construir sua percepção sobre a vida e o adoecimento. Para que tal mudança se efetive, o profissional da saúde, em sua postura e habilidade, deve saber lidar com a identidade e o protagonizar dos sujeitos individuais e coletivos; reconhecer os limites da biomedicina no tocante aos riscos e danos intrínsecos das intervenções (não somente as medicamentosas); e desenvolver uma reflexão crítica sobre a saúde e a doença na sociedade atual $70,10,12,20,24,26,36$.

\section{CONSIDERAÇÕES FINAIS}

A realização do projeto "Vivendo o SUS" é importante por fazer parte de um processo de mudança curricular. O ponto inicial do ato de planejar uma atividade que propicie um exercício de reflexão a partir de uma experiência vivenciada pelo estudante de Medicina é estimular a percepção de algumas situações, como:

- a organização do processo de trabalho na atenção básica e nas relações na equipe de trabalho, contemplando não só as relações interpessoais, mas também as de conflito, de poder, do saber, da disputa e da diversidade cultural;

- a de que a atividade realizada contribua para a formação da política de saúde, no contexto da gestão, em que quatro atores sociais possam ser identificados: usuários, trabalhadores, gestores e formadores;

- a de que a atividade realizada estimule a compreensão da informação como ferramenta de planejamento em saúde, valo- 
rizando tanto os dados epidemiológicos, como os da experiência subjetiva, que trazem a percepção dos problemas, das contradições e das insatisfações da população com a qualidade da atenção.

O processo de mudança curricular possibilita a produção de novos pactos, novos acordos institucionais, novas oportunidades e a construção de outras interpretações; possibilita, ainda, a introdução de novos saberes e novas metodologias, bem como a inovação de relações e conceitos, a identificação de novos espaços institucionais de aprendizado, migrando do hospital para a atenção básica e do saber especializado para a clínica ampliada.

A inclusão de professores de diferentes áreas do curso de Medicina no projeto "Vivendo o SUS" também permite que eles descubram serviços e práticas de saúde quase desconhecidos, tais como os do sistema público de saúde, iniciando, assim, a ruptura com a alienação e concepções geradoras de grandes vácuos no ensino da produção de práticas integrais de cuidado à saúde.

A integração da escola de Medicina com o espaço da atenção básica permite inserir o estudante, de modo mais participativo, numa realidade que possa formar um profissional mais preparado tecnicamente, mais humanizado, ético e comprometido com a comunidade. Tal integração permite, ainda, que a universidade cumpra o seu papel de produtora de conhecimentos e estratégias de novos modos de operar em saúde, modos estes mais cuidadosos, integralizáveis, com vínculos de responsabilização e resolubilidade que venham a colaborar para a construção de um sistema de saúde mais atuante, justo e ético.

\section{REFERÊNCIAS}

1. Campos GWS. A reforma de reforma: repensando a saúde. São Paulo: Hucitec; 1992.

2. Vaz N. O ensino e a Saúde: Um olhar biológico. Cad Saúde Pública. 1999;15(Supl.2): 169-76.

3. Briani MC. O ensino médico no Brasil está mudando? Rev Bras Educ Med. 2001;25(3):73-7.

4. Ministério da Saúde. Seminário Internacional "Os desafios do ensino da Atenção Básica - Graduação em Medicina; 18 - 21 jul. 2007; Brasília, DF. Brasília:[s.n.; 2007.

5. Ceccim RB, Feuerwerker LCM. Mudança na graduação das profissões de saúde sob o eixo da integralidade. Cad Saúde Pública. 2004;20(5):1400-10.

6. Oliveira GS, Koifman L. Integralidade do currículo de medicina: inovar/transformar, um desafio para o processo de formação. In: Marins JJN, Rego S, Lampert JB, Araújo JGC. Educação Médica em transformação: instrumentos para a construção de novas realidades. São Paulo: Hucitec; Rio de Janeiro: Abem; 2004. p.143-64.

7. Fernandes AS, Seclen-Palacin J, org. Experiências e desafios da atenção básica e saúde da família: caso Brasil. Brasília: OPS; 2004.

8. Merhy EE, Magalhães Júnior HM, Rimoli J, Franco TB, Bueno WS. O trabalho em saúde: olhando e experienciando o SUS no cotidiano. 2ª ed. São Paulo: Hucitec; 2004.

9. Reforma Curricular: Por Que Mudar?[acesso em 13 mar. 2008]. Disponível em:www.sorocaba.pucsp.br/atn/news php?id_news=19

10. Saippa-Oliveira G, Koifman L, Pinheiro R. Deleção de conteúdo, ensino-aprendizagem e currículo na formação em saúde. In: Pinheiro R. Ceccim RB, Mattos RB, orgs. Ensinar Saúde: a integridade e o SUS nos cursos de graduação na área da saúde. Rio de Janeiro: IMS/UERJ; Cepesc: Abrasco; 2006

11. Camargo Júnior KR. Biomedicina, saber \& ciência: uma abordagem crítica. São Paulo: Hucitec; 2003.

12. Koifman L. O modelo biomédico e a reformulação do currículo médico da Universidade Federal Fluminense. Hist Ciênc Saúde - Manguinhos. 2001;8(1):48-70.

13. Bastos ACS. Trad LAB. A família enquanto contexto de desenvolvimento humano: Implicações para a investigação em Saúde. Rev Ciênc Saúde Colet. 1998;3(1):106-15.

14. Merhy EE. Saúde: a cartografia do trabalho vivo. São Paulo: Hucitec; 2002.

15. Ministério da Educação. Ministério da Saúde. Organização Panamericana e Saúde. Programa de Incentivo às Mudanças Curriculares para as Escolas Médicas - PROMED UNIFESP. [homepage]. Brasília: Unifesp Virtual; c2005[13 mar. 2008]. Disponível em: http:/ / www.promed.unifesp.br.

16. Brasil. Programa Nacional de Reorientação da Formação Profissional em Saúde - Pró-Saúde. Disponível em: http://www.prosaude.org. Acesso em 13 de março de 2008.

17. Oliveira JA. Uma proposta para reflexão da universidade sobre a educação médica no país. Rev Bras Educ Med. 1998;12(1):p.6-9.

18. Feuerwerker LCM. Gestão dos processos de mudanças na graduação em medicina. In: Marins JJN. Rego S, Lampert JB,Araújo JGC. Educação Médica em transformação: instrumentos para a construção de novas realidades. São Paulo: Hucitec; Rio de Janeiro: Abem; 2004. 
19. Cotta RMM, Gomes AP, Maiua TM, Magalhães KA, Marques ES, Siqueira-Batista R. Pobreza, injustiça e desigualdade social: repensando a formação de profissionais de saúde. Rev Bras Educ Med. 2007;31(2):278-86.

20. Cunha MI, Marsico HL, Borges FA, Tavares P. Inovações pedagógicas na formação inicial de professores. In: Fernandes CMB, Grillo M, orgs. Educação superior: travessias e atravessamentos. Canoas: Ed. ULBRA; 2001. p.33-90.

21. Freire P. Pedagogia da autonomia: saberes necessários à prática educativa. 33aㅡ ed. São Paulo: Paz e Terra; 2006.

22. Behrens MA. O paradigma emergente e a prática pedagógica. Petrópolis: Vozes; 2005.

23. Schon D. Educando o profissional reflexivo. Porto Alegre: Artmed; 2000. 256 p.

24. Costa CRBSF, Siqueira-Batista R. As teorias do desenvolvimento moral e o ensino médico: uma reflexão pedagógica centrada na autonomia do educando. Rev Bras Educ Med 2004;28(3):242-50.

25. Costa NMSC. Docência no ensino médico: por que é tão difícil mudar? Rev Bras Educ Med. 2007;31(1):21-30.

26. Lampert JB. Tendência de Mudanças na Formação Médica no Brasil: tipologia das escolas. São Paulo: Hucitec; Rio de Janeiro: Abem; 2002.

27. Zabalza MA. O ensino universitário: seu cenário e protagonistas. São Paulo: Artmed; 2004.

28. Cunha GT. A construção da clínica ampliada na Atenção Básica. 2ª ed. São Paulo: Hucitec; 2007.

29. Marins JJN, Rego S, Lampert JB, Araújo JGC. Educação Médica em transformação: instrumentos para a construção de novas realidades. São Paulo: Hucitec; Rio de Janeiro: Abem; 2004.

30. Marins JJN. Parcerias para o desenvolvimento de territórios de aprendizagem e o trabalho de equipes matriciais em saúde. Cad Abem. 2006;2:97-8.

31. Campos GWS. Papel da rede de atenção básica em saúde na formação médica: diretrizes. Cad Abem. 2007;3:p. 6-10

32. Martins PH. Contra a desumanização da medicina: crítica sociológica das práticas médicas modernas. Petrópolis: Vozes; 2003.

33. Gonçalves RBM. Tecnologia e Organização Social das Práticas de Saude. São Paulo: Hucitec; 1994.

34. Merhy EE. Um dos Grandes Desafios para os Gestores do SUS: apostar em novos modos de fabricar os modelos de atenção. In: Merhy EE, Miranda JR. H, Rimoli J, Franco TB, Bueno WS. O Trabalho em Saúde: olhando e experienciando o SUS no cotidiano. São Paulo: Hucitec: 2003.
35. Campos GWS. Uma clínica do sujeito:por uma clínica reformulada e ampliada. In: Campos GWS. Saúde Paidéia. São Paulo: Hucitec; 2003.

36. Nogueira RP. O Trabalho em Serviço de Saúde. Organização do cuidado a partir de problemas: uma alternativa metodológica para atuação da equipe de Saúde da Família. Brasília: MS/OPAS/OMS; 2000.

37. Ceccim RB, Capozzolo AA. Educação dos profissionais de saúde e afirmação da vida: a prática clínica como resistência e criação. In: Marins JJN, Rego S, Lambert JB, Araújo JGC. Educação médica em transformação: instrumentos para a construção de novas realidades. São Paulo: Hucitec; Rio de Janeiro: Abem; 2004. p. 346-90

\section{CONTRIBUIÇÃO DOS AUTORES}

Rosana Maria Paiva dos Anjos coordenou as atividades "VIVENDOOSUS", sendo a principal responsável pela concepção e desenho deste estudo. Também elaborou os instrumentos que foram utilizados e estabeleceu as parcerias junto à rede básica para a viabilização do projeto. Orientou os alunos na organização dos dados, na análise e interpretação das informações assim como da redação do texto, Prof. Dr. Reinaldo José Gianini- participou da concepção inicial deste estudo, na definição do desenho final e aplicou a metodologia estabelecida junto aos grupos de alunos, divididos em Unidades de Saúde na rede básica municipal. Acompanhou todos os passos no desenvolvimento do trabalho. Fêz a revisão final do artigo encaminhado para publicação RBEM.

Prof ${ }^{\text {a }}$ Fátima Cristina Minari - participou neste estudo aplicando a metodologia estabelecida junto aos grupos de alunos, divididos em Unidades de Saúde na rede básica municipal. Também na capacitação dos trabalhadores e na aplicação dos instrumentos destinados às coletas de dados. Acompanhou a redação escrita final.

Bolsista Ana Helena Seabra de Luca - participou no desenho do trabalho, na elaboração da introdução, pesquisando as citações bibliográficas. Também se empenhou na organização e na informatização dos dados. E na elaboração dos resultados e discussão do trabalho, cujo relatório final foi aprovado pelo CEPE.

Aluno Mauro Paiva Rodrigues - organizou os dados revendo as informações. Também participou da pesquisa, leitura das referências bibliográficas, da redação e digitação final do artigo, elaboração das tabelas e do resumo em português e da versão em inglês. 


\section{CONFLITO DE INTERESSES}

Declarou não haver.

\section{ENDEREÇO PARA CORRESPONDÊNCIA}

Departamento de Medicina - Centro de Ciências Médicas e da saúde.
Pontifícia Universidade Católica de São Paulo

Praça Doutor José Ermírio de Moraes, 290

Jardim Vergueiro- Sorocaba

CEP.18030-095 SP Cx Postal 1570

E-mail: rmpaiva@pucsp.br 